and Meniotrix ${ }^{\circledR}$ ), with repeat samples collected two months later. We also recorded blood and sputum eosinophil counts, radiological findings such as bronchiectasis and bronchial wall thickening, total IgE, smoking status, exacerbations in the last year and ITU admissions.

Results 101 patients were followed up (69 asthma, 32 fungal) 67 female, mean (SD) age 53 (15) years, FEV1 69 (21.9)\% predicted, ICS dose 1818 (1244) $\mu$ g, and BMI 29.9 (8.9) kg/m². Specific antibody levels and responses to vaccination are presented in Figure 1. Immune deficiency at baseline and post vaccination did not correlate with lung function, radiological findings such as bronchial wall thickening or exacerbation frequency.

Conclusion Specific antibody deficiency is commonly seen in patients with asthma and fungal disease. Vaccination can provide protection and should be considered in this patient group. We need further analysis with a larger cohort of patients to study the association between antibody deficiency, lung function, radiological changes and disease progression.

\section{P244 HAEMOGLOBIN MEDIATED PROLIFERATION AND IL-6 RELEASE IN HUMAN PULMONARY ARTERY ENDOTHELIAL CELLS: A ROLE FOR CD163 AND IMPLICATIONS FOR PULMONARY VASCULAR REMODELLING}

L Ramakrishnan, A Anwar, JS Wort, GJ Quinlan. Vascular Biology Group, NHLI, Imperial College London, London, UK

\subsection{6/thoraxjnl-2016-209333.387}

Introduction Pulmonary arterial hypertension (PAH) is characterised by vascular remodelling of pulmonary arterioles. Disrupted iron homeostasis as well as subclinical haemolysis are implicated in PAH, although exact mechanisms remain unknown. IL-6, a proinflamatory cytokine and regulator of iron homeostasis is elevated in $\mathrm{PAH}$ patients and also been implicated in pulmonary vascular remodelling in murine models.

Objectives In this study we explored the influences of free haemoglobin $(\mathrm{Hb})$ on proliferative responses and secondary mediator, IL-6 release in human pulmonary artery endothelial cells (hPAECs).

\section{IL-6 release after $24 \mathrm{~h}$}

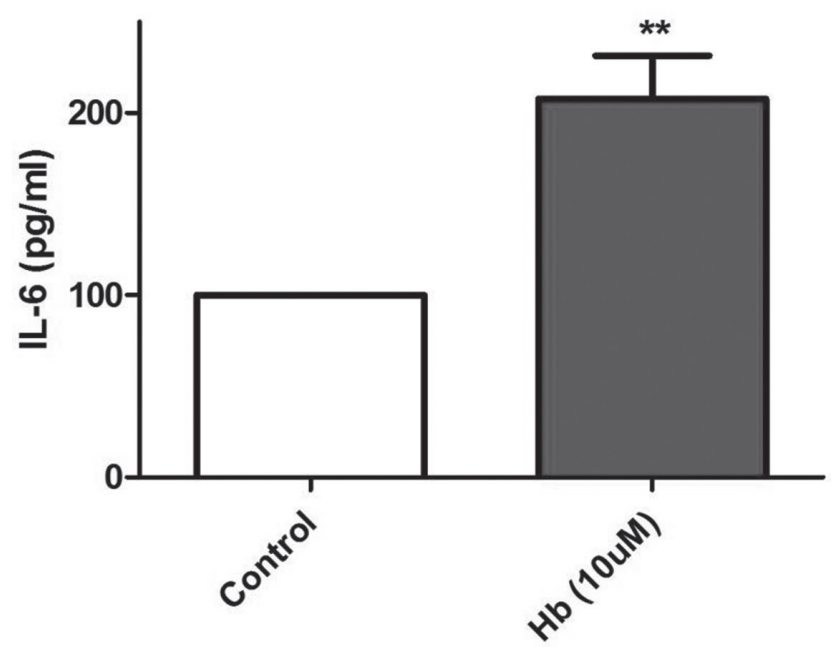

Abstract P244 Figure 1 IL-6 relaese after $24 \mathrm{~h}$
Methods Cells were challenged with $\mathrm{Hb}(10 \mathrm{uM})$ and/or IL-6 (1$10 \mathrm{ng} / \mathrm{mL}$ ). Transcriptional regulation was analysed by RT-PCR, protein expression by immunocytochemistry, secretion by ELISA and proliferation by BrdU incorporation.

Results Novel findings demonstrate that $\mathrm{Hb}$ and IL-6 individually and in combination increased proliferation of hPAECs (by $32 \%$, $47 \%$ and $63 \%$ respectively; $\mathrm{p}<0.05$ ). CD163, a Hb scavenger receptor, was basally expressed as mRNA and protein (cell surface) on hPAECs and further modulated by $\mathrm{Hb}$ or IL-6 exposure. $\mathrm{Hb}$ treatment also caused increased transcription (30\%; $\mathrm{p}<0.05)$ and release of IL-6 (107\%; $\mathrm{p}<0.01)$ from hPAECs.

Conclusion This is the first report of $\mathrm{Hb}$-mediated proliferation, CD163 expression and IL-6 release in hPAECs with potential implications for autocrine and paracrine signalling in pulmonary vasculature. $\mathrm{Hb}$ uptake may be facilitated via CD163. These studies may provide novel insights regarding mechanisms for haemoglobin driven proliferative and second messenger responses of relevance to $\mathrm{PAH}$.

\section{P245 WHOLE BLOOD LEVELS OF MICRORNA-34A PREDICT SURVIVAL AND REGULATE GENES ASSOCIATED WITH PULMONARY ARTERIAL HYPERTENSION}

J Lin, J Iremonger, J Pickworth, A Rothman, H Casbolt, N Arnold, C Elliot, R Condliffe, D Kiely, A Lawrie. University of Sheffield, Sheffield, UK

\subsection{6/thoraxjnl-2016-209333.388}

Introduction Despite advanced therapies for pulmonary arterial hypertension (PAH), the hyperproliferative pulmonary vasculopathy persists. Circulatory microRNAs (miR) offer considerable promise as both a prognostic biomarker, and to identify molecular mechanisms underlying PAH. Previous study from our lab identified whole blood miR-34a as downregulated in patients with PAH.

Objectives To validate changes in whole blood miR-34a levels in patients with $\mathrm{PAH}$ and relate them to disease severity and survival, and determine the phenotypic effect on pulmonary artery smooth muscle cells (PASMC).

Methods Whole blood RNA was isolated from 27 treatmentnaive patients with $\mathrm{PAH}, 12$ age-matched healthy volunteers (HV) and experimental models of PAH (Monocrotaline-MCT, Sugen5416/hypoxia-SuHx and controls, $\mathrm{n}=5$ /group). Whole blood miR-34a-5p and $-3 p$ levels were measured by $q P C R$. The phenotypic effect of miR-34a-5p and $-3 p$ levels was assessed on PASMC in-vitro. Differences between groups were determined by Student's t-test or ANOVA-Tukey.

Results Whole blood miR-34a-5p was reduced in patients with PAH $(\mathrm{p}<0.0001)$ and experimental models of PAH (MCT $\mathrm{p}<0.05$, SuHx $\mathrm{p}<0.001)$. Receiver operating characteristic curve identified that miR-34a-5p levels discriminates patients with PAH from HV (AUC $=0.86, p=0.001$ ). MiR-34a-5p levels were significantly lower in patients with severe $\mathrm{PAH}$, as defined by a cardiac index of $<2$ vs $>2.51 / \mathrm{min} / \mathrm{m}^{2}(\mathrm{p}<0.05$ ) and NT-proBNP > 300 vs $<300 \mathrm{ng} / \mathrm{l}(\mathrm{p}<0.001)$ and predict survival at 5 years. MiR-34a-5p levels were negatively correlated with pulmonary vascular resistance $(\mathrm{r}=-0.4, \mathrm{p}<0.05)$ and pulmonary arterial wedge pressure $(\mathrm{r}=-0.4, \mathrm{p}<0.05)$. Preliminary data showed that whole blood miR-34a-3p was reduced in patients with PAH $(\mathrm{p}=0.0267)$ and experimental models of PAH (MCT p < 0.01, SuHx p < 0.01); and delineates patients with PAH from HV (AUC $=0.925, \mathrm{P}=0.01$ ). Transfection of PDGF-stimulated PASMC with miR-34a-5p or $-3 p$ inhibitor 